\title{
Applying the 2011 Canadian guidelines for breast cancer screening in practice
}

\author{
Ellen Warner MD MSc, Ruth Heisey MD, June C. Carroll MD
}

See also practice article by Scaranelo at www.cmaj.ca/lookup/doi/10.1503/cmaj.110008

$\mathrm{F}$ or decades, women have been alarmed by the " 1 in 9" lifetime prevalence statistic for breast cancer ${ }^{1}$ while being reassured that, by participating in screening, early detection was their best hope for survival. At the same time, primary care physicians have been encouraged to increase mammography screening rates, with some provinces providing financial incentives for doing so. It is little wonder, then, that updated guidelines from the Canadian Task Force on Preventive Health Care that recommend against screening for women at average risk and younger than 50 years of age, in addition to reducing the frequency of screening for women at average risk of any age, ${ }^{2}$ have generated so much controversy.

The purpose of this article is to help health care providers understand the differences between the previous and updated guidelines and the practical implications of these changes.

The updated guidelines only apply to screening mammography for women at average risk. Breast cancer screening looks for subclinical breast cancer in a woman with no symptoms of the disease. Should a woman, 30 years of age or older, have a suspicious breast symptom such as a lump or bloody discharge from her nipple, a clinical breast examination (including the regional lymph nodes) and diagnostic mammogram are warranted. For women under the age of 30 years, ultrasound is the first diagnostic test. ${ }^{3}$

\section{How is average risk defined?}

The Task Force defines average risk as no personal or family history of breast cancer, no known $B R C A 1$ or BRCA2 mutation or no history of exposure of the chest wall to radiation. They further define "family history" as a first-degree relative with breast cancer. However, this is an oversimplification; by this definition, certain women at mod- erately increased risk or even high risk for breast cancer may be assumed to be at average risk and not offered appropriate screening.

The literature shows that women who lack a first-degree relative with a history of breast cancer, but who have one or more second- or thirddegree relatives with a history of breast or ovarian cancer, may be at higher-than-average risk for breast cancer. Thus, it is essential that a thorough family history be taken (particularly for patients of Jewish ethnicity) to ensure that women are offered risk-based screening and, if appropriate, genetic counselling. ${ }^{4.5}$

Women who have had biopsies showing atypical hyperplasia or lobular carcinoma in situ, ${ }^{6}$ in addition to most women with a personal history of invasive or noninvasive breast cancer, should be considered at moderately increased risk (16\%-25\% lifetime risk) compared with the general population.

Women are considered to be at high risk (> 25\% lifetime risk) for breast cancer if they meet any of the following criteria: they carry a mutation of the BRCA1 or BRCA2 genes; they have a first-degree relative who carries a $B R C A l$ or $B R C A 2$ mutation, but they themselves have

\section{KEY POINTS}

- All women should undergo a personalized risk assessment for breast cancer that is updated regularly.

- All women should be encouraged to start biennial screening mammography by 50 years of age.

- No woman at average risk for breast cancer should be denied the option of screening starting at 40 years of age; however, decisionmaking should be guided by a discussion that includes the woman's values and preferences.

- Women at moderately increased risk of breast cancer should be encouraged to start annual screening by 40 years of age using both mammography and clinical breast examinations.

- Women at high risk of breast cancer should begin annual screening by 30 years of age using magnetic resonance imaging, mammography and clinical breast examinations. 
not had genetic testing; they have a family history suggesting an inherited predisposition based on hereditary risk models or formal genetic assessment; they have a combination of risk factors that confers high risk according to validated models (Table 1) $;^{7,8}$ or they have a history of exposure of the chest wall to radiation. ${ }^{9}$

Recommendations for screening in these groups of women at higher risk are provided at the end of this article.

\section{What has changed in the updated guidelines?}

Canadian guidelines on breast cancer screening were first published in $1994^{10}$ and updated in 2001. ${ }^{11,12}$ The US Task Force on Preventive Health Care last updated its guidelines in 2009. ${ }^{13}$

One of the most important ways in which the new Canadian guidelines differ from the older Canadian and recent US guidelines is the change the Canadian task force made in how it grades recommendations. No longer are there categories such as "C" (no recommendation either for or against) or "I" (insufficient evidence to make a recommendation). Now, there are only 2 grades: strong or weak recommendations based on high-, moderate- or low-quality evidence in support of or against a particular screening manoeuvre. ${ }^{2}$

There was already a recommendation against monthly breast self-examination in 2001, based on the results of 2 randomized trials. Women were subsequently advised to promptly report any breast changes or concerns. ${ }^{12}$ However, the new Canadian guidelines ${ }^{2}$ differ from the old ones in the following ways (Table 2):

- The recommendation against routine screening mammography for women aged 40-49 years

- The recommendation for mammography screening every 2-3 years for women aged 50-69 years

- The extension of the recommendation for mammography screening to include women aged 70-74 years

- The recommendation against clinical breast examination at any age.

It should be noted that all of the current recommendations are classified as weak and based on moderate- or low-quality evidence. According to the GRADE (Grades of Recommendation, Assessment, Development and Evaluation) guidelines used by the task force, "weak recommendations are those for which the desirable

Table 1: Tools for assessing risk of breast cancer

\begin{tabular}{|c|c|c|c|c|}
\hline Tool & Factors included & Outcomes calculated & Validated & Comments \\
\hline $\begin{array}{l}\text { National Cancer } \\
\text { Institute breast cancer } \\
\text { risk assessment tool } \\
\text { (Gail model)* }\end{array}$ & $\begin{array}{l}\text { - Age } \\
\text { - Age at menarche } \\
\text { - Age at first live birth } \\
\text { - Number of first-degree relatives } \\
\text { with breast cancer } \\
\text { - Race/ethnicity } \\
\text { - Previous breast biopsies } \\
\text { - No } \\
\text { - Presence of atypical hyperplasia }\end{array}$ & $\begin{array}{l}\text { - Estimated 5-yr risk } \\
\text { - Estimated lifetime } \\
\text { risk }\end{array}$ & Yes $^{7}$ & $\begin{array}{l}\text { Performs poorly } \\
\text { when patient has } \\
\text { substantial family } \\
\text { history }\end{array}$ \\
\hline
\end{tabular}

International Breast Cancer Intervention Society risk evaluation toolt
- Age

- Height and weight

- Age at menarche and menopause

- Use and duration of hormone replacement therapy

- Detailed family history

- First- and second-degree relatives

- Age of onset

- Bilateral breast cancer

- Ovarian cancer

- Previous breast biopsies

- Hyperplasia/atypia/lobular

carcinoma in situ
- Estimated 10-yr risk Yes (but median

- Estimated lifetime follow-up $<6 \mathrm{yr})^{8}$ risk 
effects probably outweigh the undesirable effects (weak recommendation for an intervention) or undesirable effects probably outweigh the desirable effects (weak recommendation against an intervention) but uncertainty exists" (available at www.gradeworkinggroup.org). Thus, a weak recommendation implies that although most people in the situation would want the recommended course of action, there are many who would not. This means that clinicians need to recognize that different choices will be appropriate for different women, and they must help each woman arrive at a management decision consistent with her own values and preferences. We will deal with each of these recommendations in turn.

\section{Mammography screening in women aged 40-49 years}

"For women aged 40-49 years, we recommend not routinely screening for breast cancer with mammography. (Weak recommendation; moderate-quality evidence)"

Meta-analysis of the 9 randomized trials of screening mammography in this age group used in the updated guidelines showed a statistically significant reduction in breast cancer mortality of $15 \%$ on an "intention-to-treat" basis. ${ }^{2}$ Because these trials were conducted $30-50$ years ago, it is quite possible that they may underestimate the benefits of mammography because of improvements in technology (particularly with digital mammography) and in the ability of radiologists to interpret the results of imaging. In addition, it is possible that mammography has less effect on mortality given today's more effective adjuvant therapies. Nevertheless, mammography can now detect smaller cancers than it did previously in some cases, obviating the need for mastectomy or chemotherapy.
Therefore, women must balance the small probability that they will benefit from screening against the relatively high probability of a falsepositive result, the risk of overdiagnosis (although this is difficult to estimate) and the small possibility of radiation-induced cancers. These harms are all greater for women in their 40s than for older women. Accordingly, guidelines for women aged 40-49 years differ markedly, with a recommendation against mammography screening from the updated Canadian guidelines at one extreme, and the American College of Obstetricians and Gynecologists advocating annual mammography at the other. ${ }^{14}$

However, although the Canadian guidelines give a weak recommendation against routine screening, the authors state that "this recommendation places a relatively low value on a very small absolute decrease in mortality ... [C]linicians should discuss the benefits and harms with their patients and must help each woman to make a decision that is consistent with her values and preferences ... [b]ecause it is likely that the benefit increases in a continuous fashion with increasing age (rather than a sharp increase at 50 years of age) ..." ${ }^{2}$ This statement is almost identical to that of the 2009 guidelines from the US Preventive Services Task Force, which did not give a recommendation either for or against routine screening for this age group (Table 2). Both guidelines seem to support a tailored approach to discussing the benefits and harms of screening.

\section{Mammography screening for women aged 50-69 years}

"For women aged 50-69 years, we recommend routinely screening for breast cancer with mammography every two to three years. (Weak recommendation; moderate-quality evidence)" ${ }^{2}$

The rationale for changing the screening

Table 2: Comparison of guidelines for breast cancer screening

\begin{tabular}{|c|c|c|c|c|c|c|}
\hline Age, yr & Mammography & CBE & Mammography & CBE & Mammography & CBE \\
\hline $40-49$ & $\begin{array}{l}\text { No } \\
\text { recommendation } \\
\text { either for or } \\
\text { against (every } \\
12-18 \mathrm{mo} \text { ) }\end{array}$ & Every 1-2 yr & $\begin{array}{l}\text { No } \\
\text { recommendation } \\
\text { either for or } \\
\text { against (every } 2 \text { yr) }\end{array}$ & $\begin{array}{l}\text { Insufficient } \\
\text { evidence }\end{array}$ & $\begin{array}{l}\text { Recommend } \\
\text { against }\end{array}$ & $\begin{array}{l}\text { Recommend } \\
\text { against }\end{array}$ \\
\hline $50-69$ & Every 1-2 yr & Every $1-2$ yr & Every 2 yr & $\begin{array}{l}\text { Insufficient } \\
\text { evidence }\end{array}$ & Every 2-3 yr & $\begin{array}{l}\text { Recommend } \\
\text { against }\end{array}$ \\
\hline 70-74 & $\begin{array}{l}\text { Insufficient } \\
\text { evidence }\end{array}$ & Every 1-2 yr & Every 2 yr & $\begin{array}{l}\text { Insufficient } \\
\text { evidence }\end{array}$ & Every 2-3 yr & $\begin{array}{l}\text { Recommend } \\
\text { against }\end{array}$ \\
\hline
\end{tabular}


interval from every $1-2$ years to every $2-3$ years rests on 2 pieces of evidence. First, although the screening interval in the randomized trials ranged from 12 to 33 months, no apparent advantage of more frequent screening was seen. ${ }^{2}$ Second, in a UK trial in which women who underwent a single screening mammogram were subsequently randomized to annual screening for 3 years (study group) or to a second screening 3 years later (control group), ${ }^{15}$ although the tumours found in those screened annually were significantly smaller $(p=0.05)$ than those found in the control group, no difference was seen in predicted breast cancer mortality. Overall, 10\% more cancers were detected in the study group, but this difference was not statistically significant. Based on this study, the screening interval in the UK is 3 years. There is substantially more data from breast cancer screening programs and modelling studies supporting an interval of 2 years. ${ }^{16}$ These studies show that at least $80 \%$ of the benefit of annual screening is preserved with biennial screening, at half the cost and with almost half the number of false-positive results. None of these studies examined 3-year screening intervals. Practically speaking, because women often delay screening by several months after referral, we believe a targeted screening interval of 2 years would be prudent and grounded in evidence.

\section{Mammography screening for women aged $\mathbf{7 0 - 7 4}$ years}

"For women aged 70-74 years, we recommend routinely screening for breast cancer with mammography every two to three years. (Weak recommendation; low quality evidence)" ${ }^{\prime 2}$

Only 2 of the randomized trials used in the updated guidelines included women in this age group, and there was no significant reduction in breast cancer mortality in either study. Because of the higher incidence of breast cancer in this age group, the higher sensitivity (generally due to lower breast density) and specificity of mammography and increasing life expectancy, it is tempting to include older women in screening recommendations. However, because older women have more competing causes of death and generally more indolent cancers than younger women, breast screening may indeed be of little or no benefit. Again, we believe a tailored approach is warranted. If a woman desires to continue screening mammography, it seems justified if her life expectancy exceeds 5-10 years.

\section{Clinical breast examination}

"We recommend not routinely performing clinical breast examinations alone or in conjunction with mammography to screen for breast cancer. (Weak recommendation; low-quality evidence)"2

Although clinical breast examination consistently picks up a small percentage of cancers missed by mammography, there is currently no evidence that it finds them at a significantly earlier stage or results in fewer deaths from breast cancer. Unfortunately, no study comparing screening mammography with and without clinical breast examination has been done. Studies are underway to compare clinical breast examination with no screening in countries where screening mammography is not available. It would be surprising if these studies show a benefit in mortality, given that monthly breast selfexamination, which has a higher chance of detecting abnormalities at an earlier stage because of its frequency and the familiarity of a woman with her own breasts, does not. In the meantime, because clinical breast examination has a substantial rate of false-positive results, a recommendation against its regularly scheduled use for screening women at average risk seems reasonable. However, opportunistic screening with a clinical breast examination in the context of a general physical examination might allow a cancer to be diagnosed earlier, thereby reducing treatment morbidity. In addition, such an examination would be an opportunity for the physician to reinforce breast awareness, and for the patient to report symptoms that she might otherwise have been reluctant to mention. ${ }^{17}$ For these reasons, we suggest that physical examination of the breasts be included when women undergo a thorough physical examination as part of their periodic health examination or baseline antenatal examination.

It is important to impress upon women that any persistent new breast symptom or change warrants a visit to their health care provider for a diagnostic clinical breast examination (often followed by diagnostic imaging and surgical referral).

\section{How should screening be done for women at higher risk?}

Based on the balance of available evidence, most experts would recommend that women at moderately increased risk for breast cancer undergo annual mammography and clinical breast examination no later than 40 years of age. ${ }^{18}$ Women at high risk should be offered annual screening with magnetic resonance imaging in addition to mammography starting at 30 years of age. ${ }^{9}$

Addtional resources for physicians and patients are outlined in Appendix 1 (available at www .cmaj.ca/lookup/suppl/doi:10.1503/cmaj.120392 /-/DC1). 


\section{References}

1. Breast cancer overview. In: Canadian Cancer Encyclopedia Toronto (ON): Canadian Cancer Society; 2012. Available: http: //info.cancer.ca/cce-ecc/default.aspx?toc $=10 \&$ Lang=E (accessed 2012 Aug. 16).

2. Recommendations on screening for breast cancer in average-risk women aged 40-74 years. CMAJ 2011;183:1991-2001.

3. Parikh JR. ACR appropriateness criteria on palpable breast masses. J Am Coll Radiol 2007;4:285-8.

4. Carroll JC, Heisey R, Warner E. Family history and breast cancer. CMAJ 2012;184:1391.

5. Wolff TA, Wilson JE. Genetic risk assessment and BRCA mutation testing for breast and ovarian cancer susceptibility. Am Fam Physician 2006;74:1759-60

6. Costa A, Zanini V. Precancerous lesions of the breast. Nat Clin Pract Oncol 2008;5:700-4.

7. Decarli A, Calza S, Masala G, et al. Gail model for prediction of absolute risk of invasive breast cancer: independent evaluation in the Florence-European Prospective Investigation Into Cancer and Nutrition cohort. J Natl Cancer Inst 2006;98:1686-93.

8. Amir E, Evans DG, Shenton A, et al. Evaluation of breast cance risk assessment packages in the Family History Evaluation and Screening Programme. J Med Genet 2003;40:807-14.

9. Saslow D, Boetes C, Burke W, et al. American Cancer Society guidelines for breast screening with MRI as an adjunct to mammography. CA Cancer J Clin 2007;57:75-89.

10. Morrison BJ. Screening for breast cancer. In: The Canadian guide to clinical preventive health care. Ottawa $(\mathrm{ON})$ : Health Canada; 1994.

11. Ringash J. Canadian Task Force on Preventive Health Care. Preventive health care, 2001 update: screening mammography among women aged 40-49 years at average risk of breast cancer. CMAJ 2001;164:469-76.

12. Baxter N. with the Canadian Task Force on Preventive Health Care. Preventive health care, 2001 update: Should women be routinely taught breast self-examination to screen for breast cancer? CMAJ 2001;164:1837-46.

13. Nelson HD, Tyne K, Naik A, et al. Screening for breast cancer: an update for the US Preventive Services Task Force. Ann Intern Med 2009;151:727-37.

14. The American College of Obstetricians and Gynecologists. Prac- tice bulletin: breast cancer screening. Obstet Gynecol 2011:118: $372-82$

15. The Breast Cancer Screening Trial Group. The frequency of breast cancer screening: results from the UKCCCR Randomised Trial. Eur J Cancer 2002;38:1458-64.

16. Mandelblatt JS, Cronin KA, Bailey S, et al. Effects of mammography screening under different screening schedules: model estimates of potential benefits and harms. Ann Intern Med 2009; 151:738-47

17. Diratzouian H, Freedman GM, Hanlon AL, et al. Importance of physical examination in the absence of a mammographic abnormality for the detection of early-stage breast cancer. Clin Breast Cancer 2005;6:330-3.

18. Armstrong K, Moye E, Williams S, et al. Screening mammography in women 40 to 49 years of age: a systematic review for the American College of Physicians. Ann Intern Med 2007;146:516-26.

Affiliations: From the Odette Cancer Centre (Warner), Sunnybrook Health Sciences Centre; Women's College Hospital (Heisey); and the Department of Surgical Oncology (Carroll), Princess Margaret Hospital, Toronto, Ont.

Contributors: All of the authors contributed to the conception of the article and the interpretation of the data reviewed, drafted and revised the article for important intellectual content, and approved the final version submitted for publication.

$C M A J$ remains committed to notifying readers in a timely way about advisories and warnings pertaining to serious adverse drug events. A collection of recent drug advisories from Health Canada and the US Food and Drug Administration is regularly updated at www.cmaj.ca/misc /advisories.xhtml.

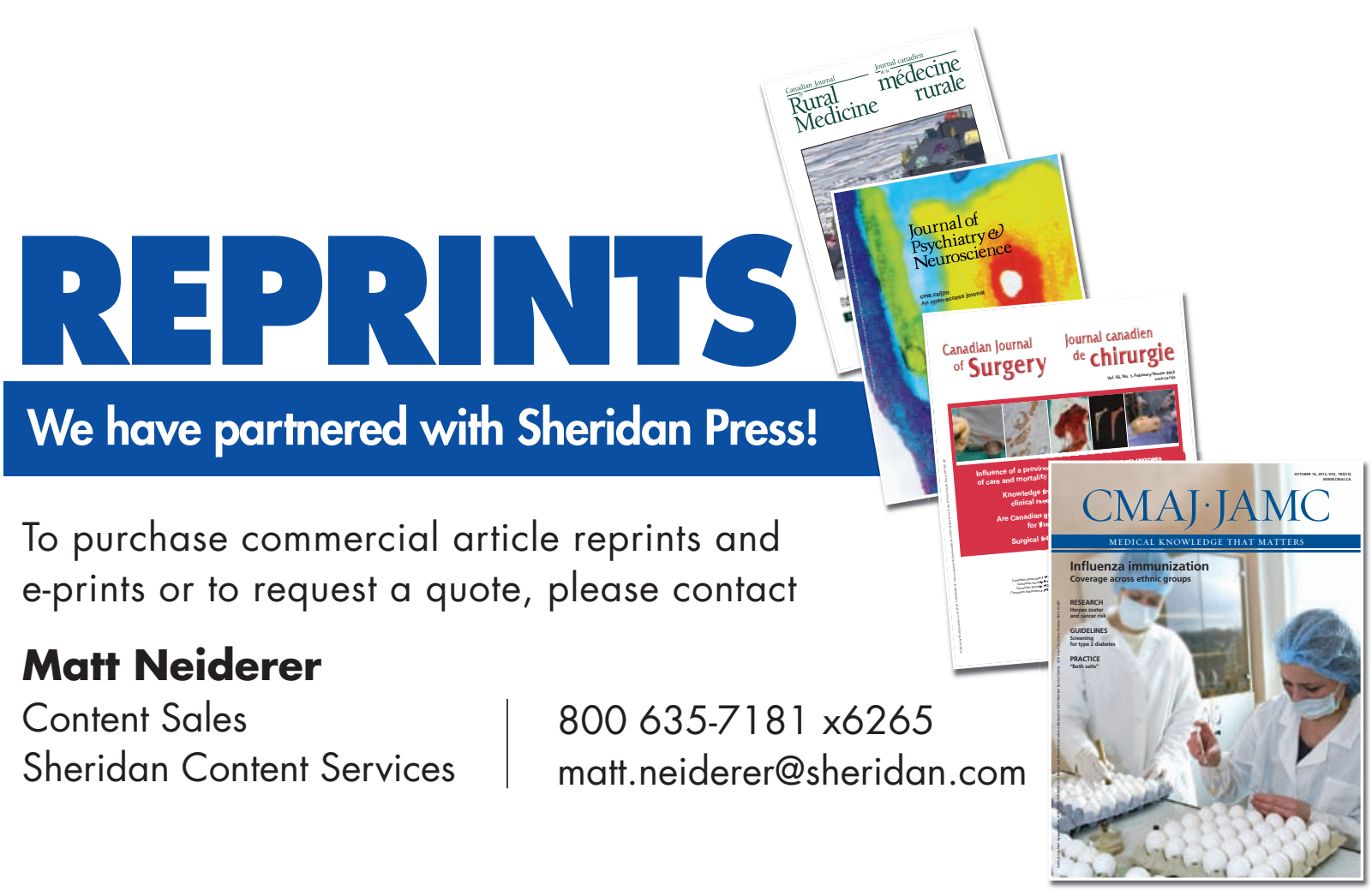

